Research Article

\title{
Ground Stress Distribution and Dynamic Pressure Development of Shallow Buried Coal Seam Underlying Adjacent Room Gobs
}

\author{
Ming Zhang $\left(1,{ }^{1}\right.$ Chen Cao $₫{ }^{1,2}$ and Bingjie Huo ${ }^{1}$ \\ ${ }^{1}$ College of Mining, Liaoning Technical University, Fuxin 123000, China \\ ${ }^{2}$ School of Civil, Mining and Environmental Engineering, University of Wollongong, Wollongong, NSW 2522, Australia \\ Correspondence should be addressed to Chen Cao; 2065214306@qq.com
}

Received 6 September 2020; Revised 19 January 2021; Accepted 26 July 2021; Published 9 August 2021

Academic Editor: Luca Landi

Copyright (c) 2021 Ming Zhang et al. This is an open access article distributed under the Creative Commons Attribution License, which permits unrestricted use, distribution, and reproduction in any medium, provided the original work is properly cited.

\begin{abstract}
The condition of the coal pillars remained in the room-and-pillar gobs is complicated. The stresses loaded on the pillar floor may be transmitted and overlapped. It changes the stress environment of the lower coal seam roof, leading abnormal periodic weighting. In the procedure of coal seam $3^{-1}$ mining in the Huoluowan Coal Mine, the ground stress is high while the working face passing through the room pillars of overlying coal seam $2^{-2}$, leading to hydraulic shield being broken. In this paper, theoretical analysis, numerical calculation, and similar material simulation were used to analyse the stress environment of lower seam and the effect of coal pillars remained in close-distanced upper seam. The stress transfer model was established for the room pillars of coal seam $2^{-2}$, and the stress distribution of underlying strata was obtained based on theoretical analysis. The joint action of dynamic pressure of high stress-coal pillar with movement of overlying rock strata in the working face $3^{-1}$ under the coal pillar was revealed. The results showed that the horizontal stress and vertical stress under the large coal pillar of the room gob in coal seam $2^{-2}$ were high, being from 9.7 to $15.3 \mathrm{MPa}$. The influencing depth of vertical stress ranged from $42 \mathrm{~m}$ to $58 \mathrm{~m}$. The influencing depth of horizontal stress ranged from 10 to $23 \mathrm{~m}$. The influencing range of the shear stress was from 25 to $50 \mathrm{~m}$. When the working face $3^{-1}$ was mined below the coal pillar of $20 \mathrm{~m}$ or $50 \mathrm{~m}$, abutment pressure was relatively high. The stress concentration coefficient reached 4.44-5.00. The dynamic pressure of the working face was induced by the stress overlying of the upper and lower coal seams, instability of the inverted trapezoid rock pillar above the coal pillar, and collapsing movement of the roof. The studying results were beneficial for guiding the safety mining of the coal seam $3^{-1}$ in the Huoluowan Coal Mine.
\end{abstract}

\section{Introduction}

In the shallow buried coal seam mining, the overlying strata have one single key stratum. The main roof can hardly form a stable voussoir beam structure. With the increase of the overlying strata thickness, two key strata structure could be formed. In this case, the periodic weighting generated by one key strata caving is not large, but the periodic weighting induced by the simultaneous caving of two key strata may be great, which generates great pressure on the hydraulic shields in the working face. That is, roof caving behaviour has great influence on the ground subsidence and the stability of the hydraulic supports $[1,2]$. It should be noted that, in multiple coal seams mining, the interval between the coal seams has great influence on the integrity of lower coal seam roof and magnitude of the mining induced dynamic stress $[3,4]$.

In close-distanced multiple coal seams mining, the room gob was formed in upper coal seam when the room retreat mining method was used. It has great influence on the stress condition of overlying strata of the lower coal seam. The geo-conditions and mechanical properties of overlying strata dominate the deformational behaviour surrounding rock [5-9]. In the mining procedure, the underlying strata may experience stress concentration, unloading or circular loading, which leads to various deformations or even fracturing of the lower seam [10-13]. The stress change of lower seam may cause gas emission and absorption, 
affecting gas migration [14-17], which may induce dynamic disasters $[18,19]$. The remaining coal pillars with different dimensions lead to different the stress concentration factors on the floor, which generates the variation of the stress environment in the lower coal seam [20]. Since the residual stress of the room gob is quite complicated, previous studies on multi-seam mining commonly adopted semitheoretical and semiempirical approaches, and most of them are case based. Jie [21] proposed that a composite beam structure was existed in the upper overlying rock strata above the room and pillar gob. The different caving periods of the upper and lower cantilever beams would induce different periodic distances and abutment pressures, which is the main reason for the overloading of the shield supports at the working face. The caving behaviour of the overlying rock strata is related to the elastic energy accumulation within the rock mass, which affect the strata deformation, ground subsidence, and mining-induced dynamic pressure [22-24]. Yang [25] believed that the roof caving was mainly the slippage instability between the strata around the working face. Li et al. [26] proposed that the main reason in leading to support shield crash was the abutment pressure induced by the suspended roof behind the working face. Zhao et al. [27] monitored the support shield working resistance under the intact coal, room gob, and room pillars with different dimensions of upper seam. For the stress transfer rule of the coal pillar floor, the influence of the remained coal pillars in the gob on the floor stress and energy distribution were studied based on theoretical analysis and numerical simulation methods [28-31]. Among them, Zhang et al. [30] used the improved composite structure mechanics method and numerical simulation to study the load transfer rule of the coal pillar group and the roof structure. Numerical method was also employed to study the stress field of the remaining coal pillar floor [32-34] and the coupling effect of the overlapped coal pillar, and mining activities were studied. Men et al. [35] analysed the rock mass movement of the inclined coal seam along the longwall face dip direction using theoretical analysis, numerical simulation, and in situ observation; the relationship between the coal seam dip angle and the coal pillar stress was obtained.

However, less research has been conducted on the stress influence on the lower coal seam and the floor stress transferring with different coal pillar sizes in the room gob. Moreover, the mining-induced dynamic pressure at the working face when crossing through large coal pillar still needs to be further studied. In this paper, the longwall face in coal seam $3^{-1}$ with adjacent room gob in the coal seam $2^{-2}$ in the Huoluowan Coal Mine was studied using theoretical analysis, numerical simulation, and similar material simulation methods.

\section{Engineering Background}

The average buried depth of the coal seam $3^{-1}$ in the Huoluowan Coal Mine was $178 \mathrm{~m}$ and with average thickness of $3.86 \mathrm{~m}$. It belonged to the medium thick to thick coal seam. The dip angle was from $0^{\circ}$ to $3^{\circ}$. The variation of the coal seam thickness was small. The coal seam structure was simple and stable. The mining method is longwall retreat mining along the strike direction.

The room gob in coal seam $2^{-2}$ was located $30 \mathrm{~m}$ above the coal seam $3^{-1}$. The width of the room pillar was $6 \mathrm{~m}$, and the width of the coal pillar was $8 \mathrm{~m}$. The average thickness of the $2^{-2}$ coal seam was $5.36 \mathrm{~m}$. To avoid large-area roof collapse, the mining area was isolated by pillars to $90 \mathrm{~m}$ subareas. The isolating coal pillars were $20 \mathrm{~m}$ or $50 \mathrm{~m}$ according to the roof conditions, as shown in Figure 1. The mechanical parameters of coal and rock were measured in the geological exploration, summarised in Table 1.

\section{Influence of Coal Pillars on the Upper Seam Gob}

3.1. Stability of the Room Pillars and the Isolating Coal Pillars. When the load of the coal pillars is beyond its strength, pillar failure occurs. Its instability judgement was [36]

$$
K \geq \frac{\sigma_{p}}{\sigma_{c 1}}\left(0.778+0.222 \frac{w}{h}\right),
$$

where $K$ is the safety coefficient; $\sigma_{p}$ is the average bearing stress of the coal pillar, $\mathrm{MPa} ; \sigma_{c 1}$ is the uniaxial compressive strength (UCS) of the coal, which equals $15 \mathrm{MPa}$ for coal seam $2^{-2} ; w$ is the room pillar width, $\mathrm{m}$; and $h$ is the height of the coal pillar, $\mathrm{m}$.

The average stress of the room pillar " $6 \times 8$ " is

$$
\sigma_{6 \times 8}=\frac{\gamma H(w+a)(a+l)}{w l}=3.5 \gamma H
$$

where $\gamma$ was the average unit weight of the coal and rock strata, around $2.4 \mathrm{~g} / \mathrm{cm}^{3} ; H$ was the buried depth of the room pillar, $148 \mathrm{~m}$; $a$ was the width of the coal room, $6 \mathrm{~m}$; and $l$ was the length of the room pillar, $6 \mathrm{~m}$. Substituting the corresponding values into equation (1) led to the safety coefficient $K=1.41$.

When $K>1.5$, the abutment pressure is mainly concentrated at the centre of the coal pillar. The coal pillar can bear the load from the overlying rock strata to maintain long-term stability. With $K$ decreases, the maximum stress of the coal pillar gradually moved from the centre of the coal pillar. The coal pillar generates plastic deformation or even failure from the outside to inside of the pillar. It finally leads to the instability of the whole coal pillar. The coal pillar cannot maintain the long-term stability if $K<1.5$. Therefore, it can be inferred that the room pillar of $8 \mathrm{~m}$ would collapse finally.

The load of the isolated coal pillar was induced by the weight of the overlying strata and abutment pressure. For simplifying, plane analysis was used to avoid 3D space problem. A homogeneous overlying rock strata was assumed to simply the complicated nonhomogeneous and anisotropic rock strata. The influence of the stress concentration at the margin of the coal pillar, the movement of the overlying rock strata, and the abutment pressure of the coal pillar was neglected.

The room pillar of $8 \mathrm{~m}$ was instability. The fractured coal mass was rushed into the gob. Fractured coal mass has 


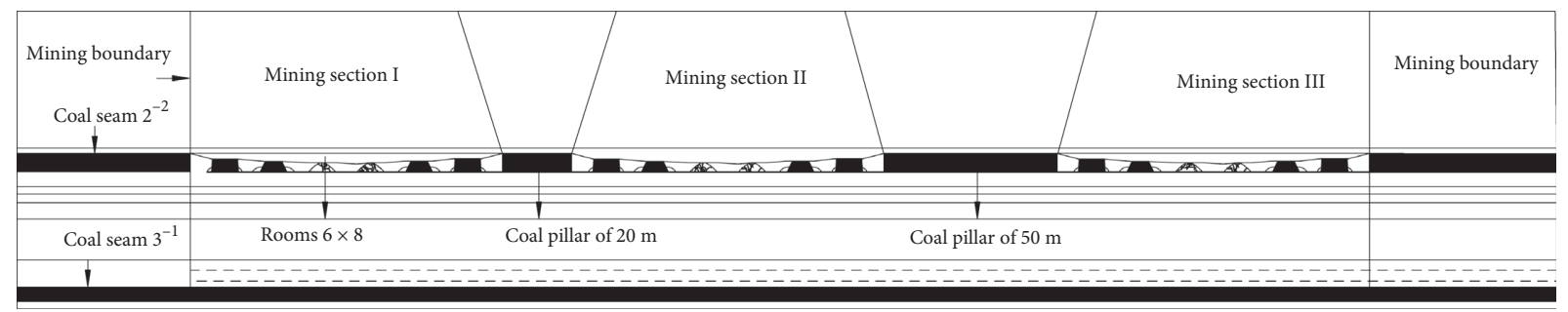

FIgURE 1: Characters of coal pillars in the room gob in coal seam $2^{-2}$.

TABLE 1: Mechanical parameters of the coal seam $2^{-2}-3^{-1}$ in the Huoluowan Coal Mine.

\begin{tabular}{|c|c|c|c|c|c|c|}
\hline Rock strata & Property & $\begin{array}{l}\text { Thickness } \\
(\mathrm{m})\end{array}$ & $\begin{array}{l}\text { Volume force }(\mathrm{kN} / \\
\left.\mathrm{m}^{3}\right)\end{array}$ & $\begin{array}{c}\text { Tensile strength } \\
(\mathrm{MPa})\end{array}$ & $\begin{array}{l}\text { Shear modulus } \\
(\mathrm{GPa})\end{array}$ & $\begin{array}{c}\text { Bulk modulus } \\
(\mathrm{GPa})\end{array}$ \\
\hline Fine sandstone & Key rock strata & 20.26 & 23.53 & 1.95 & 3.97 & 6.02 \\
\hline $\begin{array}{l}\text { Sandy } \\
\text { mudstone }\end{array}$ & r & 1.51 & 23.3 & 2.18 & 4.21 & 6.12 \\
\hline Coal seam $2^{-2}$ & - & 5.36 & 14.7 & 0.82 & 0.67 & 1.60 \\
\hline Mudstone & - & 4.21 & 23.8 & 1.58 & 2.73 & 4.35 \\
\hline $\begin{array}{l}\text { Sandy } \\
\text { mudstone }\end{array}$ & - & 2.09 & 23.3 & 2.18 & 4.21 & 6.12 \\
\hline Fine sandstone & - & 2.54 & 23.53 & 1.95 & 3.97 & 6.02 \\
\hline $\begin{array}{l}\text { Sandy } \\
\text { mudstone }\end{array}$ & - & 4.7 & 23.3 & 2.18 & 4.21 & 6.12 \\
\hline Fine sandstone & $\begin{array}{c}\text { Second key rock } \\
\text { strata }\end{array}$ & 11.71 & 23.53 & 1.95 & 3.97 & 6.02 \\
\hline Siltstone & - & 7.86 & 22.09 & 4.24 & 3.46 & 5.26 \\
\hline $\begin{array}{l}\text { Sandy } \\
\text { mudstone }\end{array}$ & - & 1.88 & 23.3 & 2.18 & 4.21 & 6.12 \\
\hline Coal seam $3^{-1}$ & - & 4.16 & 14.7 & 0.82 & 0.67 & 1.60 \\
\hline Mudstone & - & 1.94 & 23.8 & 2.18 & 2.73 & 4.35 \\
\hline
\end{tabular}

bulking effect, the gob was fully filled by coal mass finally, and then, strata become stable. The load bearing capacity of fractured coal mass in the gob was weak. Therefore, the remaining coal pillar would bear the weight of the rock strata in the collapsing area. Coal pillars of $20 \mathrm{~m}$ and $50 \mathrm{~m}$ bear majority load of the overlying rock strata.

According to the above analysis, it was assumed that the original height of the room pillar is $h$. After the room pillar fractured, the height is $h_{1}$. Then, the following equation can be acquired:

$$
\left(h-h_{1}\right) a \times \eta \times m=h_{1} \times w \times n,
$$

where $h$ was the original height of the room pillar, $\mathrm{m} ; h_{1}$ was the height after the room pillar fractured, $\mathrm{m}$; $\eta$ was the bulk expansion coefficient of the coal mass; $n$ was the number of coal rooms, $\mathrm{m}$; and $m$ was the number of coal pillars. The bulk expansion coefficient of coal usually ranged from 1.3 to 1.5. In this calculation, 1.4 was used. Then, the parameters of the Huoluowan Coal Mine were substituted into equation (3). It can be acquired that $h_{1}=2.35 \mathrm{~m}$; that is, the shortening of the coal pillar is around $3 \mathrm{~m}$. The load that the coal pillars of $20 \mathrm{~m}$ and $50 \mathrm{~m}$ beared was

$$
\sigma_{i}=\frac{\left(\mathrm{nw}+\mathrm{ma}+w_{i}\right) \times H-0.25(\mathrm{nw}+\mathrm{ma})^{2} \cot \delta}{w_{i} / \gamma},
$$

where $w_{i}$ was the width of the coal pillar in the mining section and the isolated coal pillar, $\mathrm{m}$, and $\delta$ was the collapsing angle of the rock strata above the coal room. It can be calculated that the load of the $20 \mathrm{~m}$ and $50 \mathrm{~m}$ coal pillars is 15.3 $\mathrm{MPa}$ and 9.7 $\mathrm{MPa}$, respectively. Substituting them into equation (1), it was easy to acquire that the coal pillars of $20 \mathrm{~m}$ and $50 \mathrm{~m}$ can maintain long-term stability.

3.2. Stress Distribution under Upper Coal Pillars. Due to the long-term stable equilibrium, the load above the coal pillars was almost uniformly distributed. To conveniently calculate the influence of the coal pillar width, a uniform load for each segment was assumed. The loading model of the underlying strata of the coal pillars with different sizes in coal seam $2^{-2}$ in the Huoluowan Coal Mine was established, as shown in Figure 2.

The origin of the coordinate was set at the right boundary of the coal pillar; $M_{1}$ and $M_{8}$ indicate the isolating coal pillars of $20 \mathrm{~m}$ and $50 \mathrm{~m}$ in coal seam $2^{-2}$, respectively. The loads of coal pillars in $M_{1}$ and $M_{8}$ were $\lambda_{1} q_{0}$ and $\lambda_{2} q_{0}$, where $\lambda_{1}$ and $\lambda_{2}$ were stress concentration coefficient and $q_{0}$ was the intact stress of the coal seam. The widths were $L_{1}$ and $L_{4}$. The load of room pillars after $M_{2}-M_{7}$ failure is $\lambda_{3} q_{0}$. And, the width was $L_{3}$. The coal room width was $L_{2}$. According to the loading condition and geometry of the 


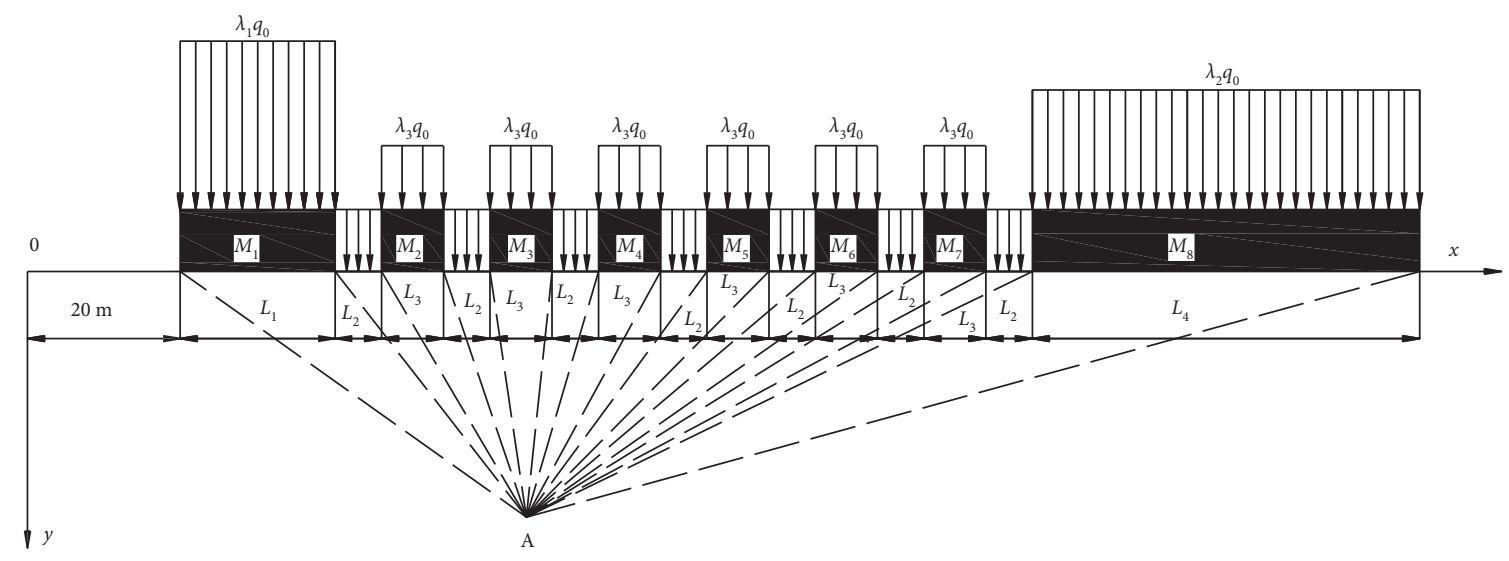

FIgURE 2: Loading model of the floor rock strata of the coal seam $2^{-2}$.

rock strata in different zones in the coal seam, the load of different zones in coal seam $2^{-2}$, the distance between two sides of each zone, and the coordinate origin ( $a$ and $b$ ) are shown in Table 2.

The coal pillar floor stress transfer equations under the uniform loading condition are [37]

$$
\begin{aligned}
\sigma_{x} & =-\frac{q_{0}}{2 \pi}\left[2\left(\theta_{2}-\theta_{1}\right)+\left(\sin 2 \theta_{2}-\sin 2 \theta_{1}\right)\right] \\
\sigma_{y} & =-\frac{q_{0}}{2 \pi}\left[2\left(\theta_{2}-\theta_{1}\right)-\left(\sin 2 \theta_{2}-\sin 2 \theta_{1}\right)\right] \\
\tau_{x y} & =-\frac{q_{0}}{2 \pi}\left(\cos 2 \theta_{2}-\cos 2 \theta_{1}\right), \\
\theta_{1} & =\arctan \frac{y_{A}-a}{x_{A}} \\
\theta_{2} & =\arctan \frac{y_{A}-b}{x_{A}}
\end{aligned}
$$

where $\sigma_{x}$ was the horizontal stress of an arbitrary point $A$ in the rock strata below the coal pillar; $\sigma_{y}$ was the vertical stress of point $A ; \tau_{x y}$ was the shear stress of point $A ; \theta_{1}$ and $\theta_{2}$ were the vertical intersection angles between point $A$ and the two boundary positions of the coal pillar; $X_{A}$ and $X_{B}$ were the vertical and horizontal coordinates of the point $A$; and $a$ and $b$ were the distances between the coordinate origin and the right and left boundaries of the coal pillar.

According to equations (5)-(8), the vertical stress applied to point A by each coal pillar in the lower coal seam can be calculated. Through superposition, the vertical stress that all coal pillars applied on it can be calculated. The dimension of the instable room pillar in the room gob in the coal seam $2^{-2}$ was $8 \mathrm{~m}$. The dimension of the isolated coal pillars was $20 \mathrm{~m}$ and $50 \mathrm{~m}$. Then, $L_{1}=20 \mathrm{~m}, L_{2}=6 \mathrm{~m}, L_{3}=8 \mathrm{~m}$, and $L_{4}=50 \mathrm{~m}$. According to the above theoretical calculation, the software of MATLAB was applied. Then, the stress distribution contour was acquired, as shown in Figure 3.

According to Figure 3(a), the vertical stress in the middle of the gob in the mining section II was relatively small. The stress disturbing under room pillars of $8 \mathrm{~m}$ was relatively small. The influencing depth is from $5 \mathrm{~m}$ to $8 \mathrm{~m}$. Around the coal pillars of $20 \mathrm{~m}$ and $50 \mathrm{~m}$, the vertical stress was high. It influences the lower rock strata up to $42 \mathrm{~m}$ and $58 \mathrm{~m}$, respectively. According to Figure 3(b), the influence of the room pillar of $8 \mathrm{~m}$ was relatively small, up to $4 \mathrm{~m}$. Around the coal pillars of $20 \mathrm{~m}$ and $50 \mathrm{~m}$, the horizontal stress has influence on the lower rock strata in the range of $10-18 \mathrm{~m}$ and 16-23 m. According to Figure 3(c), the coal pillar of $8 \mathrm{~m}$ has already been damaged. It cannot transfer shear stress. The shear stress mainly concentrated at the boundary of two sides of the coal pillars of $20 \mathrm{~m}$ and $50 \mathrm{~m}$. Their influencing depths on the lower rock strata were $25-30 \mathrm{~m}$ and $30-50 \mathrm{~m}$, respectively. The shear stress below the coal pillar shows the reversed symmetric distribution pattern. It suggests that shear failure was likely occurred when mining the coal seam $3^{-1}$ under coal pillars of $20 \mathrm{~m}$ and $50 \mathrm{~m}$.

The vertical stress and horizontal stress under coal pillars of $20 \mathrm{~m}$ and $50 \mathrm{~m}$ were relatively high. It accumulates large amount of elastic-plastic energy. Furthermore, the influencing range of the vertical stress was from $42 \mathrm{~m}$ to $58 \mathrm{~m}$; however, the distance between two coal seams was only $30 \mathrm{~m}$. Mining activity was influenced by the stress concentration of coal pillars of $20 \mathrm{~m}$ and $50 \mathrm{~m}$. The influencing range of shear stress of coal pillars $20 \mathrm{~m}$ and $50 \mathrm{~m}$ was relatively larger. However, the magnitude was relatively small. It suggests that when the working face coal seam of $3^{-1}$ crossed the above room gob, high ground stress could appear.

3.3. Roof Structure and Dynamic Mechanism. Much research has been conducted on the dynamic pressure. Most of them regard the instability of the three-hinged structure of the key block. However, according to the stability equation of the voussoir beam and the geological condition in the Huoluowan Coal Mine, the key block of the main roof can easily form two structures around the edge of the large coal pillar. One of them is the voussoir beam whose rupture line is inside of the coal pillar. It was believed that when the rupture line is inside of the coal pillar, due to the supporting effect of the lower rock strata, the load would not completely transfer to the main roof above the lower coal seam when the structural block lost stability. In this case, the stress at the working face would be weak [38]. 
TABLE 2: Loading and geometric parameters of different zones in the gob of the coal seam $2^{-2}$.

\begin{tabular}{lcccccccc}
\hline Different coal pillars & $M_{1}$ & $M_{2}$ & $M_{3}$ & $M_{4}$ & $M_{5}$ & $M_{6}$ & $M_{7}$ & $M_{8}$ \\
\hline$q$ & $\lambda_{1} q_{0}$ & $\lambda_{2} q_{0}$ & $\lambda_{2} q_{0}$ & $\lambda_{2} q_{0}$ & $\lambda_{2} q_{0}$ & $\lambda_{2} q_{0}$ & $\lambda_{2} q_{0}$ & $\lambda_{1} q_{0}$ \\
$a$ & 20 & $20+L_{1}+L_{2}$ & $\ldots$ & $\ldots$ & $\ldots$ & $\ldots$ & $\ldots$ & $20+L_{1}+7 L_{2}+6 L_{3}$ \\
$b$ & $20+L_{1}$ & $20+L_{1}+L_{2}+L_{3}$ & $\ldots$ & $\ldots$ & $\ldots$ & $\ldots$ & $\ldots$ & $20+L_{1}+7 L_{2}+6 L_{3}+L_{4}$ \\
\hline
\end{tabular}

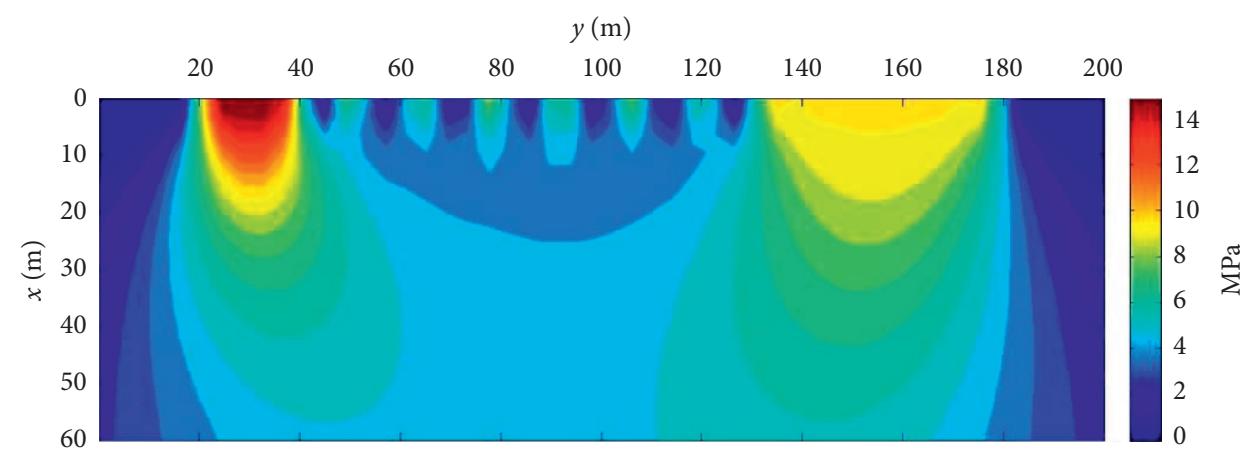

(a)

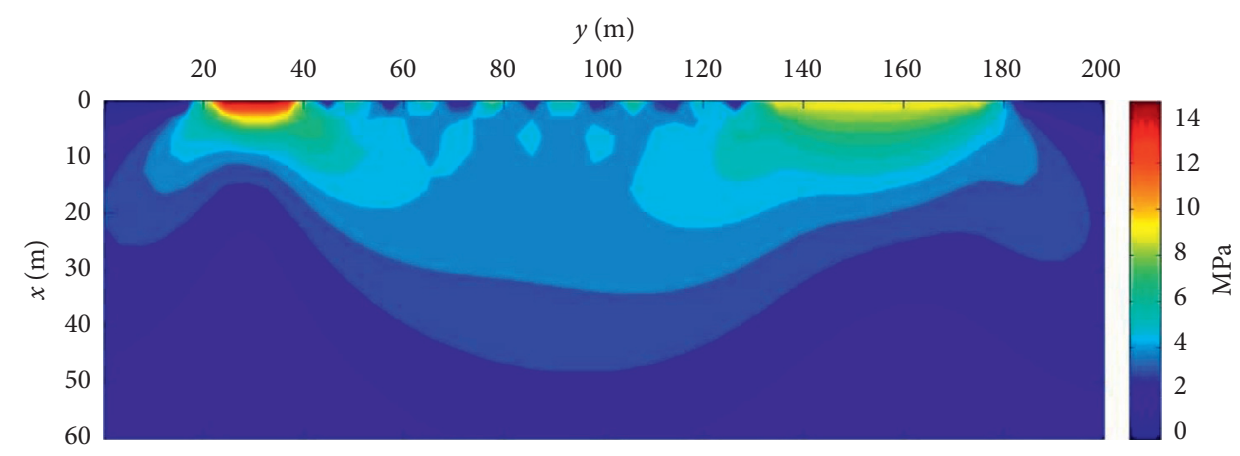

(b)

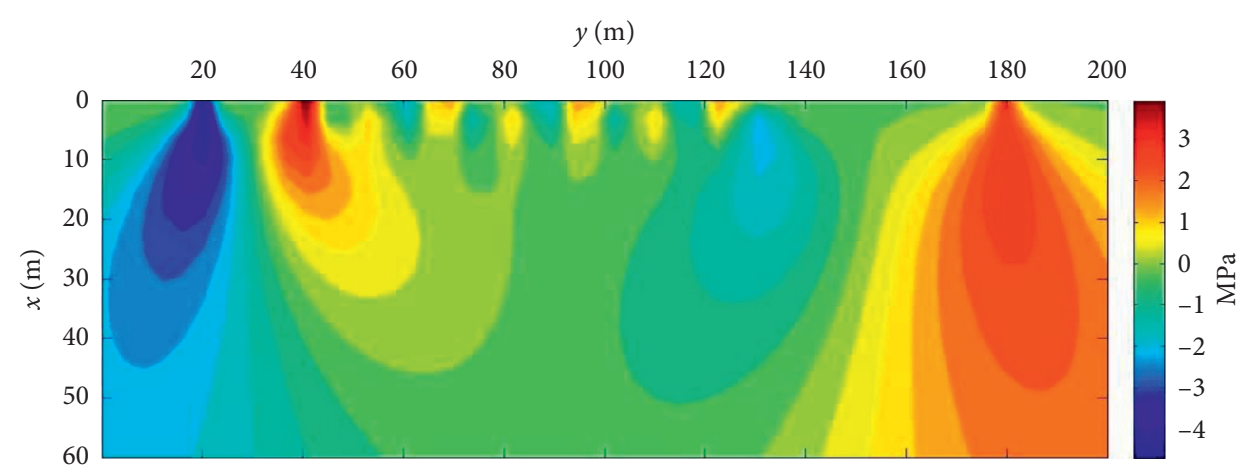

(c)

Figure 3: Stress contour under the upper seam floor. (a) Vertical stress. (b) Horizontal stress. (c) Shear stress.

The dynamic pressure phenomenon was different in the Huoluowan Coal Mine. It means that the key block along the large coal pillar side has already slipped and lost stability in advance. There was no acting force on the key block above the coal pillar and the key block along two sides. So, the main key block had relatively large rotation space, as shown in Figure 4.

The working face stress in the coal seam $3^{-1}$ below the large coal pillar was concentrated. The stress of two coal seam layers was overlaid. The second key strata below the coal pillar was easy caving behind working face. The overlying strata between coal seams caved. The pressure at working face was relatively violent and frequent.

When the coal under the pillar was gradually exploited, the upper seam coal pillar was not able to steadily support the weight of the overlying rock strata. Furthermore, it was easy to be cut off along the edge of the coal pillar influencing range. Then, dynamic impact was applied on the second key rock strata. At this time, the dynamic mine pressure was different from the previous. Not only did it have an impact 


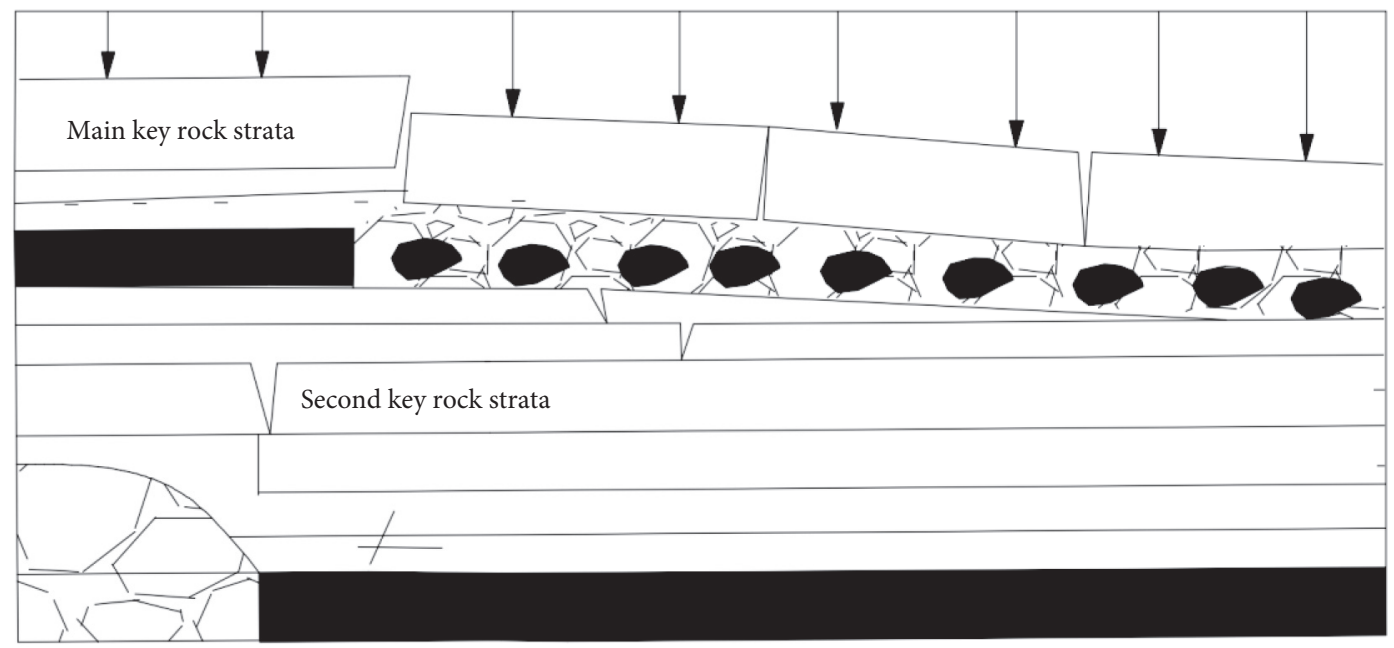

FIgURE 4: The roof structure when coal pillars were mined.

on the working face, but also it caused damage to the retreat roadway to a certain distance.

\section{Numerical Simulation}

4.1. Stress Field of the Coal Seam $3^{-1}$. The working faces in coal seams $2^{-2}$ and $3^{-1}$ in the Huoluowan Coal Mine were studied. According to the practical status and considering the boundary effect, isolating pillars of $50 \mathrm{~m}$ were set as two boundaries. The model dimension was $500 \mathrm{~m} \times 400 \mathrm{~m}$ $\times 200 \mathrm{~m}$. For the numerical model, the boundary condition and loading state were explained as follows: for the boundary of two sides along the direction of $X$, the displacement along the direction of $X$ was fixed. It means that for the boundary, the displacement along the direction of $X$ was zero. Similarly, the displacement of the two sides along the direction of $Y$ was fixed. The bottom boundary of the model was fixed. At the top of the model, it was free. Along the direction of $Z$, the self-weight capacity was applied. According to the measured stress data in the mine site, a stress of $4.62 \mathrm{MPa}$ was applied along the direction of $X$. Along the direction of $Y$, a stress of 2.2 MPa was applied.

After the coal seam of $2^{-2}$ was exploited, stress concentration occurred in the coal pillar. The vertical stress distributions before and after the room pillars were damaged are shown in Figure 5. Before the coal pillars was damaged, the maximum vertical stress was $14.6 \mathrm{MPa}$ and the stress concentration coefficient was 4.3. All stresses were in the central area of the coal pillar, indicating that two sides of the coal pillar have already entered the plastic zone. The relatively high stress is transferred to the internal area of the coal pillar after they lost the bearing capacity. They did not intersect in the zone where the stress concentration was maximal in the room pillar. In fact, they were located along two sides of the centre. The vertical stress in the room pillar centre were lower than that at two sides. This indicates that in the room pillar, there was still the elastic core which has certain loading capacity. After the coal pillar was damaged, the stress in the coal pillar decreased to $8.2 \mathrm{MPa}$, higher than the intact stress. This indicates that after the room pillar was damaged, it still had residual load bearing capacity.

After the coal seam $2^{-2}$ was mined, the stress field in the rock strata is shown in Figure 6. In the figure, the black break line shows the stress distribution along the perpendicular direction of the coal seam $3^{-1}$. According to the relative position relationship, it can be known that the coal seam $3^{-1}$ below the gob was in pressure-relieving area after the coal seam $2^{-2}$ was mined. The vertical stress is from $3.6 \mathrm{MPa}$ to $4.3 \mathrm{MPa}$, decreasing by $4.4 \%-20 \%$. The accumulated elastic energy in the coal seam $3^{-1}$ was effectively released. The possibility of dynamic disaster decreased, which was beneficial for the exploiting of the coal seam $3^{-1}$. However, below the coal pillars of $20 \mathrm{~m}$ and $50 \mathrm{~m}$, the pressure increases. Among them, in the coal seam $3^{-1}$, the vertical stresses were $5.9 \mathrm{MPa}$ and $5.6 \mathrm{MPa}$, respectively. The stress concentration coefficients were 1.31 and 1.24 , respectively.

4.2. Failure Characteristic of the Surrounding Rock after Upper Seam Mining. For the horizontally bedded coal seam, after the roadway was excavated, the stress distribution of the surrounding rock was relatively uniform. They often distribute symmetrically. Under the influence of the high stress, the surrounding rock masses in the working face generated plastic deformation. The mining section II was regarded as an example. It was analysed that the failure characteristic of the surrounding rock masses is shown in Figure 7 after the coal seam $2^{-2}$ was mined. It can be known that the failure zones of the surrounding rock in the working face showed a symmetric distribution. For the surrounding rock around the coal rooms, the main failure mode was tensile and shearing. For the upper strata, it was mainly of shearing failure. The room pillar of $8 \mathrm{~m}$ lost stability. For the floor below the coal pillar, there was no failure. And, this was consistent with the theoretical analysis. 


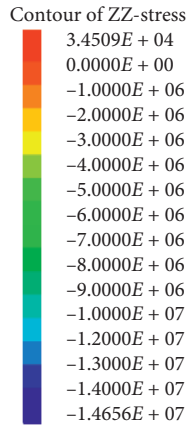

$-1.4656 E+07$

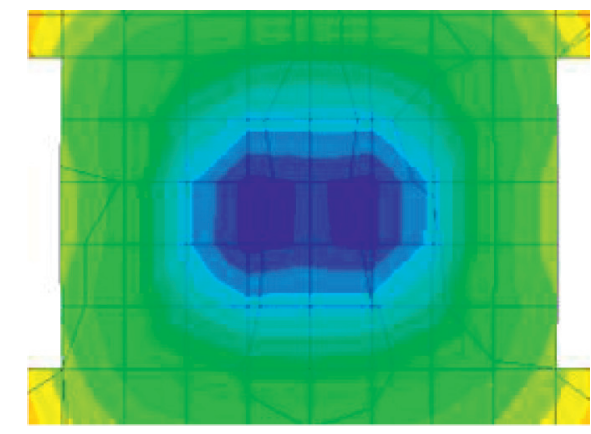

(a)
Contour of ZZ-stress

$-1.4443 E+04$

$-1.0000 E+06$

$-2.0000 E+06$

$-3.0000 E+06$

$-4.0000 E+06$

$-5.0000 E+06$

$-5.0000 E+06$
$-6.0000 E+06$

$-6.0000 E+06$
$-7.0000 E+06$

$-7.0000 E+06$

$-8.0000 E+06$

$-9.0000 E+06$

$-1.0000 E+07$

$-1.1000 E+07$

$-1.1428 E+07$

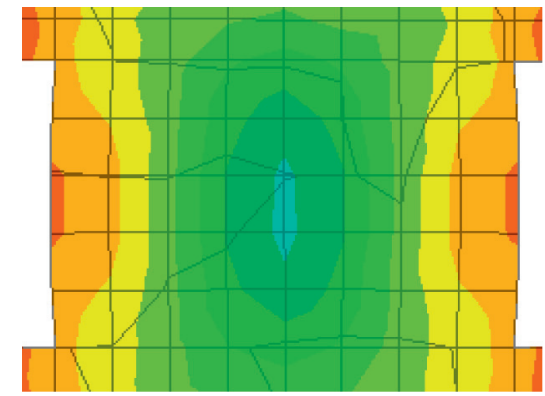

(b)

Figure 5: The vertical stress distribution before and after the room pillar was damaged. (a) Before the room pillar was damaged. (b) After the room pillar was damaged.

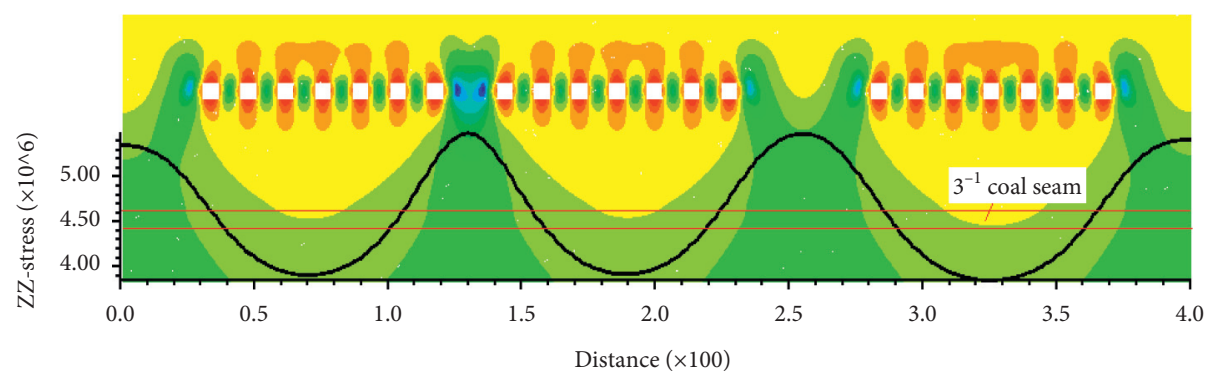

FIGURE 6: Vertical stress distribution of the coal seam $3^{-1}$ under the mining influence of coal seam $2^{-2}$.
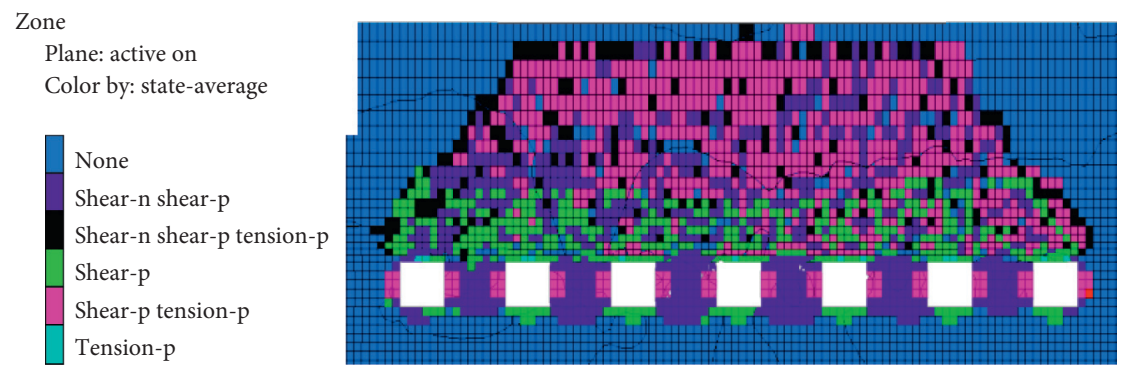

Figure 7: The plastic zone distribution in the surrounding rock.

4.3. Mining-Induced Stress under Upper Coal Pillars. When the working face advanced to $100 \mathrm{~m}$, the stress distribution in the surrounding rock is shown in Figure $8(\mathrm{a})$. The influencing range of the abutment pressure was around $52 \mathrm{~m}$ in front of the working face. The abutment pressure was around $4.5 \mathrm{MPa}$ to $21.3 \mathrm{MPa}$. The maximum abutment pressure occurred in front of the working face $6 \mathrm{~m}$. The stress concentration coefficient was around 4.73. The working face was below the coal pillar of $20 \mathrm{~m}$.

When the working face advanced to $200 \mathrm{~m}$, the stress distribution in the surrounding rock was shown in Figure $8(\mathrm{~b})$. The influencing range of the abutment pressure was around $58 \mathrm{~m}$ in front of the working face. The abutment pressure was around 4.5 $\mathrm{MPa}$ to $20.0 \mathrm{MPa}$. Among them, the maximum stress occurred in front of the working face $5.0 \mathrm{~m}$. The stress concentration coefficient was around 4.44. The working face started entering the coal pillar of $50 \mathrm{~m}$.

When the working face arrived at $240 \mathrm{~m}$, the stress distribution in the surrounding rock is shown in Figure 8(c). The influencing range of the abutment pressure was in front of the working face around $39 \mathrm{~m}$. The abutment pressure was around $4.5 \mathrm{MPa}$ to $22.5 \mathrm{MPa}$. Among them, the maximum stress occurred in front of the working face $4.0 \mathrm{~m}$. The stress concentration coefficient was around 5.00. At this point, the right boundary of the coal pillar of $50 \mathrm{~m}$ was located in front of the working face $10 \mathrm{~m}$. 


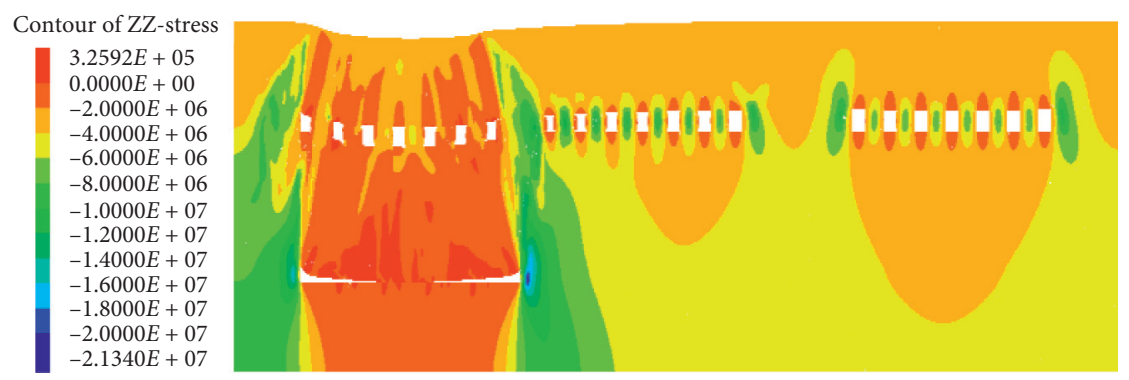

(a)
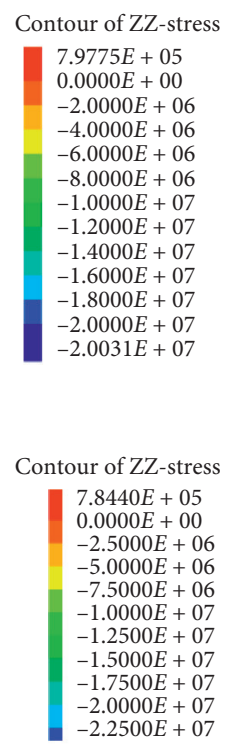

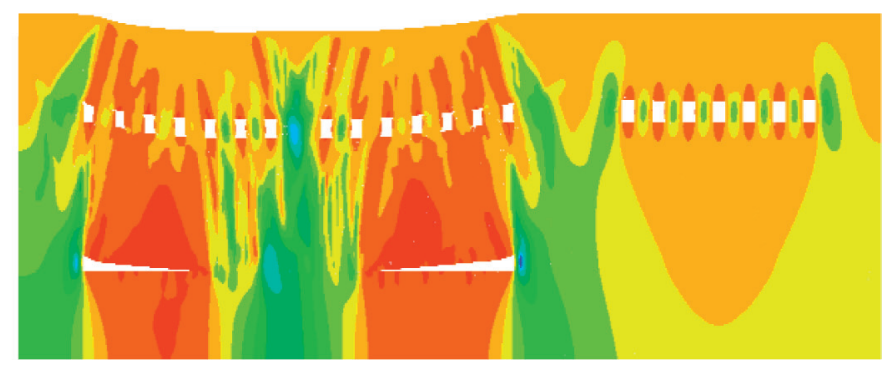

(b)

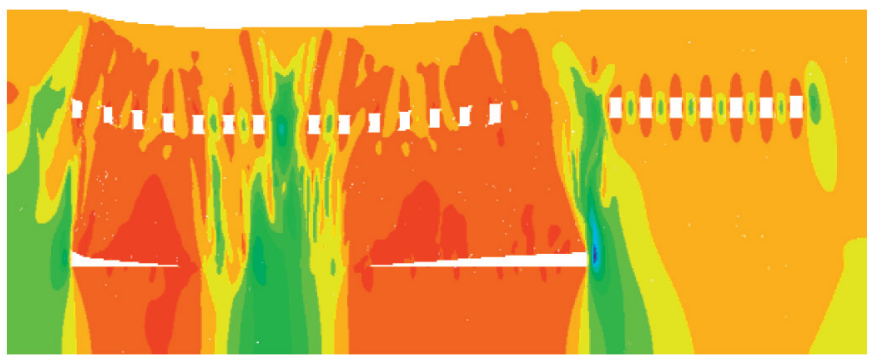

(c)

Figure 8: Stress distribution contour when the working face advancing. (a) Working face advanced to $100 \mathrm{~m}$. (b) Working face advanced to $200 \mathrm{~m}$. (c) Working face advanced to $240 \mathrm{~m}$.

\section{Similar Material Simulation Study}

5.1. Establishment of the Model. For the model, the geometric similarity ratio was $1 / 100$. For the volume weight similarity ratio, it was 0.75 (the practical volume weight was $2.4 \mathrm{~g} / \mathrm{cm}^{3}$ and the model volume weight was $\left.1.8 \mathrm{~g} / \mathrm{cm}^{3}\right)$. The filling size of the model was $5000 \mathrm{~mm} \times 400 \mathrm{~mm} \times 2000 \mathrm{~mm}$ (length $\times$ width $\times$ height). The top boundary of the model was up to the ground surface. Therefore, it was not necessary to apply pressure.

To regenerate the coal pillar in the room gob, the paraffin was used. Room retreat is simulated by heating to melt the paraffin. The coal rooms were mined and the coal pillars were remained. Then, the coal pillars were destroyed manually to simulate the instability of coal pillars. The coal pillars of $20 \mathrm{~m}$ and the large coal pillars of $50 \mathrm{~m}$ were remained, as shown in Figure 9.

5.2. Overlying Strata Movement When the Working Face Crossed Pillars. The overlying rock strata movement was studied to explain the violent dynamic pressure when crossing the coal pillar of $50 \mathrm{~m}$. Below the coal pillar of $50 \mathrm{~m}$, the roof was caved along the coal wall. The direction was basically consistent with the left boundary of the reversed trapezoid rock column. The top and bottom gobs were connected. The working face bears the weight of the interlayer strata between two coal seams and the weight of the reversed rock column above the coal pillar of $50 \mathrm{~m}$. The mine pressure appearance was violent, as shown in Figure 10(a). With the working face advancing, there was a plastic zone at the boundary of the large coal pillar. When the working face entered the right plastic zone range, the coal pillar stability was influenced. Coal pillars cannot effectively support the weight of the overlying rock strata. The coal pillar of $50 \mathrm{~m}$ and the above rock column caved. This leaded to the collapsing of the rock strata above the rock column. The fractures along two sides of the reversed trapezoid were compressed again. The acting force among rock strata was relatively large. The roof was cut along the coal wall vertically. The coal masses in the working face that was not exploited were squeezed out. Compared with the right boundary of the reversed trapezoid rock column, the direction shows the reversed symmetry form. The dynamic pressure was violent, as shown in Figure 10(b).

When the coal seam $3^{-1}$ crossed the large coal pillar, the collapsed height of overlying strata was relatively large. The 


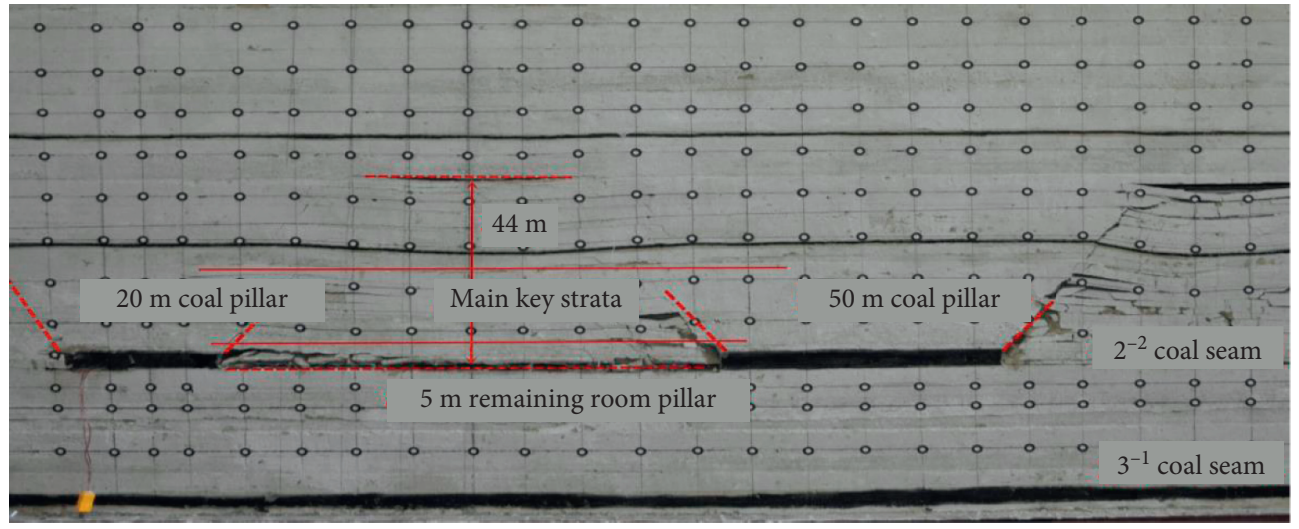

FIGURE 9: Similarity simulation of the coal pillar in the room gob.

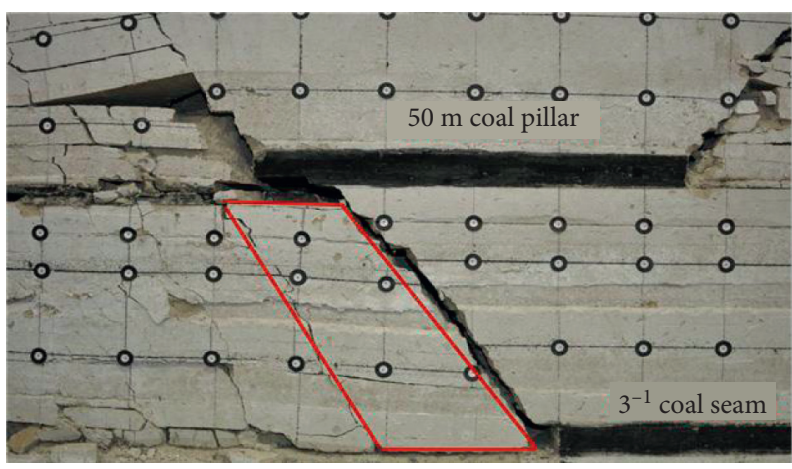

(a)

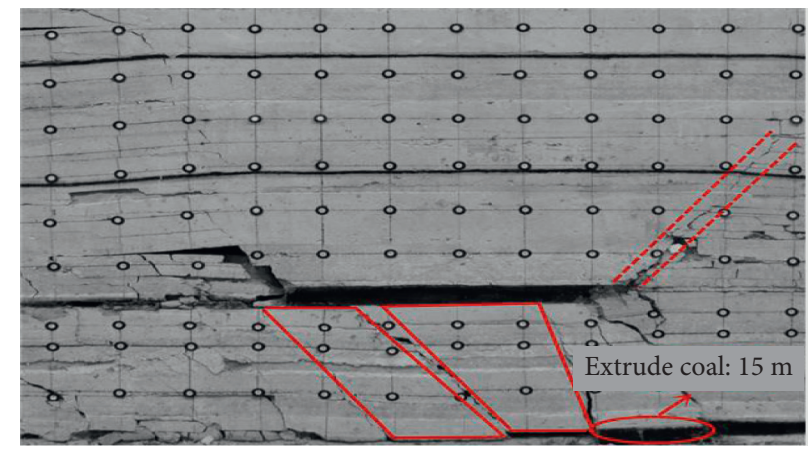

(b)

FIGURE 10: The overlying rock strata movement when crossing the coal pillar. (a) When crossing the coal pillar of $50 \mathrm{~m}$. (b) When the coal pillar of $50 \mathrm{~m}$ was mined.

stress concentration of the upper coal seam and the mining induced stress of the lower coal seam were overlaid. The rock strata between two coal seams caved thoroughly. The dynamic pressure was violent. When it was not able to support the reversed trapezoid rock column above the coal pillar of $50 \mathrm{~m}$, the high elastic-plastic energy that was accumulated released. This induced the instability of the overlying rock structure. If this impact load was applied on the working face, the accident of the hydraulic supports crush would occur.

\section{Conclusions}

(1) In the Huoluowan Coal Mine, for the room gob in the shallow buried coal seam $2^{-2}$, the stress distribution under coal pillar group was determined. When the room pillars of $8 \mathrm{~m}$ lost stability, they had disturbing effect on the stress field of the rock strata 5-8 $\mathrm{m}$ lower than the coal seam. As for the coal pillars of $20 \mathrm{~m}$ and $50 \mathrm{~m}$, the maximum influencing range on the lower rock strata was $42 \mathrm{~m}$ and $58 \mathrm{~m}$. For the lower coal seam of $3^{-1}$, the vertical stress concentration coefficients were 1.31 and 1.24, respectively.
(2) The characteristic of the abutment pressure when the working face crossed large coal pillars was revealed. The concentration coefficient reached 4.44-5.00. Moreover, it was maximal at the position in front of the working face $4-6 \mathrm{~m}$.

(3) Above the large coal pillar, there was no acting force on the key strata along two sides. Moreover, there was large rotating space. It was determined that for the working face in the coal seam $3^{-1}$, when the large coal pillars were mined, the overlying rock strata lost stability.

(4) The joint acting dynamic pressure mechanism of the working face $3^{-1}$ was revealed. Specifically, it was the high stress environment (the mining induced stresses of the lower coal seam and upper coal seam were overlaid) and the overall instability of the reversed trapezoid rock column above the coal pillar. This would induce the accident of roof cutting and the support compressing.

Mining layouts and geological conditions vary from site to site. Although our study is based on the specific mining condition, it provides guidance and reference to those studies with similar conditions. 


\section{Data Availability}

Some or all data, models, or codes generated or used during the study are included within the article and are also available from the corresponding author upon request.

\section{Conflicts of Interest}

The authors declare that they have no conflicts of interest regarding the publication of this paper.

\section{Acknowledgments}

The authors gratefully acknowledge the National Natural Science Foundation of China Project (no. 51504127) for providing partial financial support for the present study.

\section{References}

[1] Q. X. Huang, "Ground pressure behavior and definition of shallow seams," Chinese Journal of Rock Mechanics and Engineering, vol. 21, no. 8, pp. 1174-1177, 2002.

[2] Y. F. Ren and Q. X. Qi, "Study on characteristic of stress field in surrounding rocks of shallow coal face under long wall mining," Journal of China Coal Society, vol. 10, no. 36, pp. 1612-1618, 2011.

[3] Y. F. Ren, "Study on mine pressure and overlying strata movement law of contiguous seams with shallow depth," Coal Science and Technology, vol. 43, no. 7, pp. 11-14, 2015.

[4] T. Zhu, B. S. Zhang, G. R. Feng, and X. Zhang, "Roof structure and control in the lower seam mining field in the ultra-close multiple seams," Journal of China Coal Society, vol. 35, no. 2, pp. 190-193, 2010.

[5] Z. Yang, B. Tong, C. C. Huang et al., "Study on the movement law of overlying strata in mining face under room and pillar goaf," Journal of Mining \& Safety Engineering, vol. 29, no. 2, pp. 157-161, 2012.

[6] Q. S. Bai, S. H. Tu, F. T. Wang et al., "The evolution of mining stress and the mechanism of disaster caused by shallow buried coal pillar," Chinese Journal of Rock Mechanics and Engineering, vol. 31, no. S2, pp. 3772-3778, 2012.

[7] P. Małkowski, Z. Niedbalski, and T. Balarabe, "A statistical analysis of geomechanical data and its effect on rock mass numerical modeling: a case study," International Journal of Coal Science \& Technology, vol. 8, no. 4, pp. 1-12, 2020.

[8] D. Cao, A. Wang, S. Ning et al., "Coalfield structure and structural controls on coal in China," International Journal of Coal Science \& Technology, vol. 7, no. 5, pp. 220-239, 2020.

[9] S. Mao, "Development of coal geological information technologies in China," International Journal of Coal Science \& Technology, vol. 7, no. 4, pp. 320-328, 2020.

[10] J. Han, H. Liang, C. Cao, and Z. Bi, "A mechanical model for sheared joints based on Mohr-Coulomb material properties," Géotechnique Letters, vol. 8, no. 2, pp. 1-14, 2018.

[11] D. J. Xue, L. L. Lu, J. Zhou, and L. Lu, "Cluster modeling of the short-range correlation of acoustically emitted scattering signals," International Journal of Coal Science \& Technology, pp. 1-15, 2020.

[12] D. J. Xue, J. Zhou, Y. T. Liu, and L. Gau, "On the excavationinduced stress drop in damaged coal considering a coupled yield and failure criterion," International Journal of Coal Science \& Technology, vol. 7, no. 5, pp. 58-67, 2020.
[13] D. J. Xue, Y. T. Liu, H. W. Zhou, J. Q. Wang, J. F. Liu, and J. Zhou, "Fractal characterization on anisotropy and fractal reconstruction of rough surface of granite under orthogonal shear," Rock Mechanics and Rock Engineering, vol. 53, no. 3, pp. 1225-1242, 2020.

[14] L. Zhang, S. Chen, C. Zhang, X. Fang, and S. Li, "The characterization of bituminous coal microstructure and permeability by liquid nitrogen fracturing based on $\mu \mathrm{CT}$ technology," Fuel, vol. 262, Article ID 116635, 2020.

[15] L. Zhang, J. H. Li, J. H. Xue, C. Zhang, and X. Fang, "Experimental studies on the changing characteristics of the gas flow capacity on bituminous coal in CO2-ECBM and N2ECBM," Fuel, vol. 291, Article ID 120115, 2021.

[16] J. Lin, T. Ren, Y. P. Cheng, J. Nimcik, and G. Wang, "Cyclic $\mathrm{N} 2$ injection for enhanced coal seam gas recovery: a laboratory study," Energy, vol. 188, Article ID 116115, 2019.

[17] J. Lin, T. Ren, G. Wang, P. Booth, and J. Nemcik, "Experimental investigation of $\mathrm{N} 2$ injection to enhance gas drainage in CO2-rich low permeable seam," Fuel, vol. 215, pp. 665-674, 2018.

[18] B. Chen, "Stress-induced trend: the clustering feature of coal mine disasters and earthquakes in China," International Journal of Coal Science \& Technology, vol. 7, no. 4, pp. 676692, 2020.

[19] X. Wu, Y. Peng, J. Xu, Q. Yan, W. Nie, and T. Zhang, "Experimental study on evolution law for particle breakage during coal and gas outburst," International Journal of Coal Science \& Technology, vol. 7, no. 1, pp. 97-106, 2020.

[20] D. Xue, J. Wang, Y. Zhao, and H. Zhou, "Quantitative determination of mining-induced discontinuous stress drop in coal," International Journal of Rock Mechanics and Mining Sciences, vol. 111, pp. 1-11, 2018.

[21] X. Z. Jie, "Study on the characteristics of strata behavior in shallow seam longwall mining under the room-and-pillar mining goaf," Journal of China Coal Society, vol. 37, no. 6, pp. 898-902, 2012.

[22] S. H. Tu, F. J. Dou, Z. J. Wan, F. Wang, and Y. Yuan, "Strata control technology of the fully mechanized face in shallow coal seam close to the above room and pillar gob," Journal of China Coal Society, vol. 36, no. 3, pp. 366-370, 2011.

[23] X. Lian, H. Hu, T. Li, and D. Hu, "Main geological and mining factors affecting ground cracks induced by underground coal mining in Shanxi Province, China," International Journal of Coal Science \& Technology, vol. 7, no. 2, pp. 362-370, 2020.

[24] D. Xue, H. Zhou, Y. Zhao, L. Zhang, L. Deng, and X. Wang, "Real-time SEM observation of mesoscale failures under thermal-mechanical coupling sequences in granite," International Journal of Rock Mechanics and Mining Sciences, vol. 112, pp. 35-46, 2018.

[25] Z. L. Yang, "Study of controlling catastrophe for roof strata in shallow seam longwall mining," Rock and Soil Mechanics, vol. 29, no. s1, pp. 459-463, 2011.

[26] H. D. Li, H. H. Yang, B. Zhang, and G. Chen, "Control study of strong strata behaviors during the fully mechanized working face out of concentrated coal pillar in a shallow depth seam in proximity beneath a room mining goaf," Journal of China Coal Society, vol. 40, no. s1, pp. 6-11, 2015.

[27] J. Y. Zhao, S. L. Wu, J. P. Ma et al., "Study on strata behaviors regulation of coal working face under room and pillar mining goaf," China Energy and Environmental Protection, vol. 6, pp. 60-63, 2015.

[28] J. X. Yang, C. Y. Liu, and B. Yu, "The effects of load distribution exerting on coal pillars on the stress and energy 
distribution of the floor strata," Acta Montanistica Slovaca, vol. 21, pp. 102-112, 2016.

[29] S. Li, L. F. Zhou, M. K. Luo et al., "Strata behaviors analysis of stage coal pillar in Tong Xin mine caused by repeated mining," Journal of Liaoning Technical University: Natural Science, vol. 34, no. 6, pp. 661-667, 2015.

[30] S. K. Zhang, L. G. Wang, X. D. Zhang et al., "Load transfer effects of the longwall sustaining coal pillars on the safety of the mining goaf system," Journal of Safety and Environment, vol. 16, no. 3, pp. 116-119, 2016.

[31] L. Li, F. Li, Y. Zhang, D. Yang, and X. Liu, "Formation mechanism and height calculation of the caved zone and water-conducting fracture zone in solid backfill mining," International Journal of Coal Science \& Technology, vol. 7, no. 1, pp. 208-215, 2020.

[32] L. Xu, H. X. Wei, Z. Y. Xiao, and B. Li, "Engineering cases and characteristics of deviatoric stressunder coal pillar in regional floor," Coal Science and Technology, vol. 40, no. 4, pp. 23-25, 2012.

[33] Z. J. Zhu, H. W. Zhang, T. W. Lan, B. Huo, and Y. Chen, "Study on surrounding rock stress evolution law of fullymechanized top coal caving mining face under role of overlapping coal pillars," Coal Science and Technology, vol. 45, no. 3, pp. 26-31, 2017.

[34] C. Zhu, M. He, M. Karakus, X. Zhang, and Z. Tao, "Numerical simulations of the failure process of anaclinal slope physical model and control mechanism of negative Poisson's ratio cable," Bulletin of Engineering Geology and the Environment, vol. 80, no. 4, pp. 3365-3380, 2021.

[35] J. G. Men, S. Wang, R. P. Yuan et al., "Study on overburden strata structure features and stress distribution law of coal pillar in inclined seam," Coal Science and Technology, vol. 42, no. 5, pp. 21-24, 2014.

[36] M. X. Ren, "Rational decision of pillar's size of Wongawilli mining method," Journal of Mining \& Safety Engineering, vol. 21, no. 1, pp. 42-43+118, 2004.

[37] B. Yu, C. Y. Liu, J. X. Yang, and J. Liu, "Mechanism of strong pressure reveal under the influence of miningdual system of coal pillar in Datong mining area," Journal of China Coal Society, vol. 39, no. 1, pp. 40-46, 2014.

[38] J. F. Ju, "Mechanism and prevention of support crushing disaster while mining out of the upper coal pillar in close distance shallow seams," $\mathrm{PhD}$ thesis, China University of Mining and Technology, Xuzhou, China, 2013. 